\title{
The relationship between the attachment styles of the adults with and without depression and the parenting attitudes of their parents
}

\author{
Büşra Sümeyye Bıyık๑, Cengiz Akkaya $\odot$ \\ Department of Psychiatry, Bursa Uludăg University School of Medicine, Bursa, Turkey
}

\begin{abstract}
Objectives: In this study, it is aimed to determine the relationship between attachment styles of adults with and without depression and child rearing attitudes of their parents.

Methods: One hundred eighteen patients who are admitted to outpatient clinic of Department of Psychiatry of the Uludağ University School of Medicine, who are diagnosed with depression according to DSMIV-R and DSM V and put on regular medication, and 130 healthy individuals of similar demographic characteristics without any psychopathologic diagnostic, are included in this study. Within the scope of this research "Experiences in Close Relationships Inventory-II", "Child-Rearing Attitudes Scale", "Beck Depression Inventory" and Sociodemographic Information Form were used.

Results: It is found that there is a significant difference between the attachment styles of the individuals with and without depression and their parents' attitudes towards child rearing. Maternal and paternal acceptance / interest scores of the patient group were lower than those of the healthy group, and the parents' supervision / control scores were higher. The anxiety and avoidance attachment scores of the married individuals of the patient group are higher than the scores of married individuals of the healthy group.

Conclusions: High anxiety and avoidance related to attachment and controlling parental attitudes were found to be risk factors for depression.
\end{abstract}

Keywords: Attachment styles, parent child rearing attitudes, depression

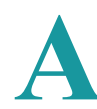

ttachment is an instinctive form of behavior that occurs between the mother (or caregiver) and the child in the early stages of life, and that follows a neurobiopsychological development path with the need of the child to be close to the mother [1].

Attachment behaviors, which are not limited to childhood only, continue in adulthood. The first relationship is established with the mother and this relationship is the basis for the relationships that will occur in other periods of life. In this article, the term "parents" will be used instead of "caregivers".

Attachment theory has been demonstrated by John Bowlby. Bowlby objected to the understanding of Freud that mother's feeding her baby is the reason of the attachment of the baby to the mother. According to Bowlby, attachment is not a process that is only developed by the elimination of basic need for the nutrients. This basic relationship the child has with his mother will affect his personality and his psychological development. In infants aged 7-15 months, baby's 
demonstration of attachment behavior is important for the development of the limbic system and the maturation of cortical attachment regions. Clinging to a baby, singing her a song or a lullaby will increase the bond between a mother and her baby and contribute to the baby's brain development [2].

In 1950, the World Health Organization asked Bowlby, who was working in the field of developmental psychiatry related with the mental health-related İssues of the homeless children, to prepare a report containing recommendations. Bowlby [3], mentioned in the first part of the report, that realization of a baby or a young child's relationship with his mother in a satisfying way giving pleasure is very important for the mental health of the baby or a young child. Bowlby and his colleagues stated that a small child had hunger for the presence and love of his mother at least as much as his hunger for food.

In the early studies on attachment, the relationship of the baby with the mother and the child's attachment behaviors during childhood were discussed. Ainsworth and his friends designed an experimental model, namely Foreign Environment Experiment, in order to observe the reactions of infants to different situations. In this study, mothers, their environment and their interactions with foreigners of the 12-18 months old babies were investigated. Ainsworth and his colleagues concluded after observations that there were three types of attachment style. These attachment styles are: safe, anxious / unstable and avoiding [4]. If the mother is sensitive and can respond to the needs of her child, the child will be securely attached; if the mother is overly controlling, inconsistent or irrelevant, the child will develop an unsafe attachment.

Later, the view of Bowlby [5] that "attachment is a process that continued from the cradle to the grave" was adopted and the boundaries of the attachment studies expanded. In their work, Hazan and Shaver [6] asked adult individuals to evaluate themselves and their partners in romantic relationships. As a result of the study, it was seen that those who established a relationship with their mothers on the basis of trust where their needs are met in childhood, were securely connected to their spouses during adulthood and established a relationship based on reciprocity. It has also been shown that adults who have been subjected to rejection by their parents during childhood have also been insecure (anxious / unstable) in their rela- tions with their spouses [6].

Together with the studies on adult attachment, new classifications for attachment styles have begun to be made. According to Bartholomew and Horowitz [7]; the basic dimensions of attachment styles are composed of positive and negative evaluation of self and others. As indicated in Table 1; while individuals who are securely connected to others have good intentions for others, they find themselves worthy of being loved. Obsessive individuals do not respect themselves, they exalt others over and they are constantly worried about being abandoned. Indifferent individuals only see themselves as valuable, their self-esteem is very high, and they refuse to establish a relationship. Fearfully attaching people find themselves worthless, they think that Noone finds them worthy of loving and find others as unreliable [8].

Development of attachment between mother and baby is very important for the survival of the baby with basic needs such as nutrition, cleansing and temperature. The prerequisite for the development of a secure attachment is that the physical needs of the baby are remedied in a timely manner and that the he feels comfortable near his mother. The lack of a secure relationship between the baby and the mother in the first years of life was thought to be the determinant of psychopathology in the later life period [9].

According to Bowlby, sadness is the usual reaction to losses and adversities in life. Depression occurs when a person reacts differently to negativities of life. Seligman explains the mood of the person who does not take a job he can manage, who does not care about their accomplishments and ignores them as luck coincidences, as "learned helplessness". According to Bowlby, this mood may be a result of some experiences in childhood and makes the person prone to depression. Bowlby is of the opinion that the children who were not appreciated by their parents in childhood and were called to be incompetent even though they did their best to meet the demands of their parents may be inclined to "learned helplessness" in the future, and this feeling of helplessness and hopelessness may lead

\section{Table 1. Attachment styles}

Self (Positive) Self (Negative)

\begin{tabular}{lcc}
\hline Others (Positive) & Confident & Obsessive \\
Others (Negative) & Indifferent & Fearful \\
\hline
\end{tabular}


to depression [10-15].

According to theory; having inconsistent and insufficient care from the parent in childhood, the individual will experience attachment anxiety in adulthood. Having constantly angry and distant parents in the childhood, the person will avoid expressing his feelings in his relations during his adulthood and will not seek closeness and support. Lack of social support is also a risk factor for depression [11].

The aim of this study is to compare adult attachment styles and parental attitudes of individuals with and without depression, and to investigate the relationship between adult attachment styles and parenting attitudes of their parents.

\section{METHODS}

A total of 118 patients ( 90 women, 28 men) of 18 65 years of age being at least primary school graduates, who were admitted to the Uludag University Medical Faculty Psychiatry outpatient clinics in the year 2017 and who had been diagnosed with depression according to DSM-IV-IV and DSM$\mathrm{V}$ criteria formerly and who are informed about the study and approved to take part in the study, participated in the data gathering process. The participants completed the questionnaires during the control interviews after diagnosis.

The study was approved by Uludağ University Faculty of Medicine Ethics Committee. The data of the healthy control group were obtained from 130 volunteers consisting of hospital staff and relatives with similar demographic characteristics.

\section{Instruments}

Sociodemographic Information Form (SIF)

The socio-demographic data form which is prepared for demographic characteristics such as gender, age, education level, marital status and income level has been applied to all participants. For the patient group, questions about their medical stories were added.

Experiences in Close Relationship Inventory-II (ECRII)

In 2000, Fraley, Waller and Brennan developed the scale "Experiences in Close Relationship InventoryII" for a measurement with a higher sensitivity than the previous scales. The reliability and validity study of the scale for the Turkish sample was conducted by Selçuk and colleagues in the year 2005. The items of the scale measure two dimensions of attachment (anxiety and avoidance). The scale, which is evaluated with 7-point Likert-type questions, consists of 36 items. From two sub dimensions scores varies between 18-126 can be obtained [12].

\section{Parenting Styles Questionnaire (PSQ)}

Scale is developed by Sümer and Güngör in 1999 based on the studies of Steinberg and colleagues as 30 items and the number of items is reduced to 22 by subsequent analysis. The scale is filled separately for the mother and father. The scale measures two dimensions of parental attitude (acceptance / attention and strict supervision / control). The scores from the scale ranged between 11 and 55 [13].

\section{Beck Depression Inventory (BDI)}

The scale developed by Beck and his colleagues in 1961 was adapted into Turkish by Hisli in 1988. On the scale consisting of 21 items of symptoms of depression, each question is evaluated between 0-3 points. The total score from the scale ranged from 0 63 [14].

\section{Statistical Analysis}

Statistical analysis of the findings obtained from the study was performed using SPSS (Statistical Package for the Social Sciences) 18 for Windows. Shapiro Wilk test was used to determine the compliance of variables to normal distribution. In the analysis of continuous variables, $t$ test for was used for Independent Samples in normal distributed data, and Mann-Whitney $U$ test was used for data not normally distributed. For the categorical variables the chi-square test was used, and when the expected frequencies were not met the Fisher Exact test was used. Significance was tested at $\mathrm{p}<0.05$ and $p<0.001$.

\section{RESULTS}

Two hundred forty-eight participants, 118 (90 females, 28 males) diagnosed with depression and 130 (100 female, 30 male) healthy volunteers are included in the study. Table 2 shows the demographic 
Table 2. Comparison of patient and healthy group in terms of demographic information

\begin{tabular}{lccc}
\hline & $\begin{array}{c}\text { Patient } \\
(\mathbf{n = 1 1 8})\end{array}$ & $\begin{array}{c}\text { Healthy } \\
(\mathbf{n}=\mathbf{1 3 0})\end{array}$ & p value \\
\hline Age (years) & $45.6 \pm 1.1$ & $37.7 \pm 1.1$ & $<0.001^{\mathrm{a}}$ \\
& $46(18-62)$ & $37(23-67)$ & \\
\hline
\end{tabular}

\section{Gender}

\begin{tabular}{|cccc|}
\hline Woman & $90(76.3 \%)$ & $100(76.9 \%)$ & $0.904^{\mathrm{b}}$ \\
\hline Man & $28(23.7 \%)$ & $30(23.1 \%)$ & \\
Marital status & & & \\
\hline Married & $79(67 \%)$ & $74(62.7 \%)$ & $<0.001^{\mathrm{b}}$ \\
\hline Single & $18(15.3 \%)$ & $39(33.1 \%)$ & \\
\hline Divorced or widow & $14(11.9 \%)$ & $2(1.7 \%)$ & \\
\hline Has a relationship & $7(5.9 \%)$ & $15(12.7 \%)$ & \\
\hline Level of education & & & \\
\hline Primary school & $47(39.8 \%)$ & $29(22.3 \%)$ & \\
\hline Middle school & $18(15.3 \%)$ & $15(11.5 \%)$ & \\
\hline High school & $19(16.1 \%)$ & $29(22.3 \%)$ & \\
\hline License and above & $34(28.8 \%)$ & $57(43.9 \%)$ & \\
\hline Employment status & & & \\
\hline Working & $42(35.6 \%)$ & $104(80 \%)$ & \\
\hline Unemployed & $64(54.2 \%)$ & $21(16.2 \%)$ & \\
\hline Retired & $12(10.2 \%)$ & $5(3.8 \%)$ & \\
\hline Monthly income & & & \\
\hline $0-1500$ & $54(45.8 \%)$ & $29(43.5 \%)$ & \\
\hline $1500-3000$ & $37(31.4 \%)$ & $61(42.5 \%)$ & $1(4.2 \%)$ \\
\hline $3000-4500$ & $20(16.9 \%)$ & $7(59.8 \%)$ & \\
\hline$>4500$ & $7(5.9 \%)$ & & \\
\hline
\end{tabular}

Data are expressed in terms of the mean \pm standard deviation, median (minimum: maximum) and $\mathrm{n}(\%)$.

${ }^{\mathrm{a}}$ Mann-Whitney U test, ${ }^{\mathrm{b}} \mathrm{Chi}-\mathrm{Square}$ test, ${ }^{\mathrm{c}}$ Fisher Exact test

characteristics of the patient and the healthy group. There is a significant difference between the patient and the healthy group in terms of marital status, education level, working status and income level $(p<$ 0.001). The education and income level of the patient group are significantly lower. In terms of the scores obtained in the study; Beck depression scores, maternal and paternal acceptance / interest scores, strict control / inspection points of the parents are significant in terms of patient and healthy group $(p<$ 0.001). The results obtained from the comparison are shown in Table 3. The Beck depression scores and parental control / inspection scores of the patient group are significantly higher than healthy group; while maternal and paternal acceptance / interest scores are lower. When the literature is examined, there is no findings that parental attitudes and attachment styles are affected by age, education level and working status variables. In order to eliminate the intermixing effect of the marital status variable, only married individuals were included in the comparison to be conducted in terms of the attachment styles between the patient and the healty gruop, considering that marital status may have an impact on the attachment style of the individual. This comparison is shown in Table 4. Different groups of participants who are single, have 
Table 3. Comparison of patient and healthy group in terms of scores obtained from the scales

\begin{tabular}{lccc}
\hline & $\begin{array}{c}\text { Patient } \\
(\mathbf{n = 1 1 8})\end{array}$ & $\begin{array}{c}\text { Healthy } \\
(\mathbf{n = 1 3 0 )}\end{array}$ & p value \\
\hline Beck depression points & $18.8 \pm 0.8$ & $7.1 \pm 0.6$ & $<0.001^{\mathrm{a}}$ \\
\hline Mother acceptance / interest points & $18(1-38)$ & $5(0-32)$ & \\
& $36.4 \pm 0.9$ & $43.5 \pm 0.7$ & $<0.001^{\mathrm{a}}$ \\
\hline Father acceptance / interest points & $38(11-55)$ & $44(11-55)$ & \\
& $32.5 \pm 0.9$ & $40.8 \pm 0.7$ & $<0.001^{\text {'a }}$ \\
\hline Mother's strict supervision / control & $32(11-52)$ & $44(19-55)$ & \\
& $34.5 \pm 0.9$ & $29.2 \pm 0.7$ & $<0.001^{\mathrm{a}}$ \\
\hline Father's strict supervision / control & $35(17-55)$ & $41(11: 52)$ & \\
& $34.5 \pm 0.8$ & $28.2 \pm 0.7$ & $<0.001^{\mathrm{b}}$ \\
\hline
\end{tabular}

Data are expressed as mean \pm standard deviation and median (minimum: maximum).

${ }^{a}$ Mann-Whitney U test, ${ }^{b}$ Independent Samples $t$ test

Table 4. Comparison of married individuals in terms of attachment scores

\begin{tabular}{lccc}
\hline & $\begin{array}{c}\text { Patient } \\
(\mathbf{n = 7 8 )}\end{array}$ & $\begin{array}{c}\text { Healthy } \\
(\mathbf{n = 7 4 )}\end{array}$ & p value \\
\hline Anxious attachment points & $66.6 \pm 2.1$ & $54.1 \pm 1.9$ & $\mathbf{< . 0 0 1}^{\mathbf{b}}$ \\
\hline Avoiding attachment points & $64(30-111)$ & $54(25-107)$ & \\
& $56.4 \pm 2.6$ & $45.3 \pm 2.1$ & $\mathbf{0 . 0 0 1}^{\mathbf{a}}$ \\
\hline
\end{tabular}

Data are expressed as mean \pm standard deviation and median (minimum: maximum).

aMann-Whitney U test, ${ }^{\mathrm{b}}$ Independent Samples t test

a relationship, are divorced and widowed were excluded from the comparison analysis because the number of participants within the each group were insufficient. With the aim of qualifying the patient profile, the clinical characteristics of the patients are presented in Table 5. The correlation between anxious and avoidance attachment scores, parental acceptance/interest and strict supervision/control scores, and depression scores of the patient group were shown in Table 6

\section{DISCUSSION}

In terms of sociodemographic characteristics evaluated in the study, the result that patients with depression are more disadvantaged than healthy individuals, is compatible with the literature. It has been seen that this difference is tried to be explained with the approaches of social selection and social causation in the literature [15].

In this study, firstly the patient group data, then the healthy group data with similar characteristics were collected. Although there were some matched groups in terms of living place and gender, it was observed that there was a difference between the patient and healthy group in terms of age, marital status, income level, education level, and working status. There were no evidence in the literature that age, income, education, and working status had an 
Table 5. Clinical presentation of the disease in the patient group

\begin{tabular}{cc}
\hline Treatment time (years) & \\
\hline $0-5$ years & $83(70.3 \%)$ \\
$6-10$ years & $20(16.9 \%)$ \\
$>10$ years & $15(12.7 \%)$
\end{tabular}

Hospitalization

$\begin{array}{lc}\text { Yes } & 14(11.9 \%) \\ \text { No } & 104(88.1 \%)\end{array}$

Number of hospitalization

$0-5$

$13(92.9 \%)$

$6-10$

$1(7.1 \%)$

\begin{tabular}{|c|c|}
\hline \multicolumn{2}{|c|}{$\begin{array}{l}\text { Hospitalization Time (for a single } \\
\text { time) }\end{array}$} \\
\hline 0-30 days & $6(42.9 \%)$ \\
\hline $30-61$ days & $6(42.9 \%)$ \\
\hline 61 - 120 days & $2(14.3 \%)$ \\
\hline
\end{tabular}

How many years ago has the disease started?

$\begin{array}{lc}0-5 & 60(50.8 \%) \\ 6-10 & 26(22 \%) \\ >10 & 32(27.2 \%)\end{array}$

Is the period of depression repeated?

Yes

$47(39.8 \%)$

No

$45(38.1 \%)$

Continued

$26(22.1 \%)$

Number of Attacks

$\begin{array}{lc}0-5 & 9(41.60 \%) \\ 6-10 & 3(6.30 \%) \\ >10 & 25(52.10 \%)\end{array}$

Medication time (year)

$\begin{array}{lc}0-5 & 94(79.6 \%) \\ 6-10 & 19(16.1 \%) \\ >10 & 5(4.24 \%)\end{array}$

Suicide

Yes

$17(14.4 \%)$

No

$101(85.6 \%)$

The data are expressed as $n(\%)$.

impact on attachment styles. However, since it was thought that marital status could affect the attachment styles, only the attachment scores of married individuals were compared. It was found that patient and married individuals were more anxious and avoidant in their emotional relations than healthy and married individuals. Since there was no evidence in the literature on the fact that the variables of age, income, marital status, education, and working status had an impact on the individual's assessment of the parental attitudes, all participants were included in the comparison between the Parenting Styles Questionnaire scores in which the adult individuals evaluated their parents retrospectively. According to the Parenting Styles Questionnaire, where parental attitudes of adults are assessed, the patient group perceives more control of their parents; while it was found that the healthy group perceived their parents as more caring and accepting. According to Bowlby, the failure to safely develop the attachment or interruption of the attachment in childhood triggers the formation of a neurotic personality in advanced ages [16]. It has been shown in a prospective study that insecure attachment is a feature of personality structure predisposed to depression [17].

Correlation analysis was performed to see the relationship between anxiety and avoidance attachment scores of the patient group, parental acceptance/interest and strict supervision/control scores, and depression scores. A significant, positive and weak correlation was found between anxiety and avoidance scores $(\mathrm{r}(118)=0.36, p=0.001)$. A significant, positive and weak correlation was found between anxiety and depression scores $(\mathrm{r}(118)=0.36$, $p=0.001)$. A significant, positive and weak correlation was found between avoidance and depression scores $(\mathrm{r}(118)=0.23, p=0.001)$. No relation was found between the depression scores and the scores regarding the parental child-rearing attitudes. A significant, negative and weak correlation was found between maternal acceptance/interest and strict supervision/control scores $(\mathrm{r}(118)=-0.20, p=0.001)$. A significant, positive and moderate correlation was found between maternal acceptance/interest and paternal acceptance/interest scores $(\mathrm{r}(118)=0.48, p$ $=0.001)$. A significant, positive and high correlation was found between maternal strict supervision/control scores and paternal strict supervision/control scores ( $\mathrm{r}$ $(118)=0.66, p=0.001)$. A significant, negative and weak relationship was found between avoidance and maternal acceptance / interest level $(\mathrm{r}=-0.34, p<$ $0.001)$. As the perceived acceptance and caring from 
Table 6. Correlation analysis between subgroups of the patient group's attachment styles and parental attitudes

\begin{tabular}{|c|c|c|c|c|c|c|c|}
\hline & ANP & AVP & МCP & МАР & FCP & FAP & DP \\
\hline ANP & - & $0.36^{* *}$ & 0.08 & -0.06 & -0.07 & 0.05 & $0.36^{* *}$ \\
\hline AVP & $0.36^{* *}$ & - & 0.09 & $-0.34 * *$ & 0.04 & -0.14 & $0.23 *$ \\
\hline MCP & 0.08 & 0.09 & - & $-0.20 *$ & $0.66^{* *}$ & -0.14 & -0.07 \\
\hline MAP & -0.06 & $-0.34 * *$ & $-0.20^{*}$ & - & -0.09 & $0.48^{* *}$ & -0.06 \\
\hline FCP & -0.07 & 0.04 & $0.66^{* *}$ & -0.09 & - & $-0.20^{*}$ & 0.05 \\
\hline FAP & 0.05 & -0.14 & -0.14 & $0.48 * *$ & $-0.20 *$ & - & -0.01 \\
\hline DP & $0.36^{* *}$ & $0.23^{*}$ & -0.07 & -0.06 & 0.05 & -0.01 & - \\
\hline
\end{tabular}

mother decreases, avoidance is increased. In our study, no relation was found between anxiety level and parental child rearing attitudes.

\section{CONCLUSION}

According to the data obtained from this study, it is observed that anxious and avoidant attachment is a depressing factor. The lack of acceptance / interest of the parent is seen to be predictive of the avoidance of the close relations of adulthood, and it is thought that the avoidant attachment is susceptible to depression, because it deprived the individual from social support. Parental control is also found to be a risk factor for depression. Parent's insufficient and inconsistent care may lead the child's mental schemes to be built on anxiety, hopelessness and despair, and these schemes make the individual prone to depression. It is considered that the studies that will be carried out with the healthy control group matching one-to-one with a large scale of the patient and the healthy group will be important in terms of investigating the causality of the findings.

\section{Authorship declaration}

All authors listed meet the authorship criteria according to the latest guidelines of the Internaional Committe of Medical Journal Editors, and all authors are in agreement with the manuscript.

\section{Conflict of interest}

The authors disclosed no conflict of interest during the preparation or publication of this manuscript.

\section{Financing}

The authors disclosed that they did not receive any grant during conduction or writing of this study.

\section{REFERENCES}

1. Yahşi G, Bayraktar S. [The effect of birth order on attachment style according to attachment theory]. Int J Soc Sci Edu Res 2016;2:256-67. [Article in Turkish]

2. Özeren GS, Akın S. [Styles of attachment to parents and evaluation of interpersonal relations]. İstanbul Bilim Üniversitesi Florence Nightingale Tip Dergisi 2016;2:222-32.[Article in Turkish]

3. Bowlby J. Attachment and Loss: Vol 1, Attachment. New York Basic Books; 1969: pp. 233-67.

4. Main M, Weston DR. Avoidance of the attachmnet figure in infancy: Descriptions and interpretations. In: Parker CM, Hinde JS, eds. The place of attachment in human behavior. London and New York: Tavistock Publications Ltd., 1982: pp. 31-59.

5. Bowlby J. Attachment and Loss: Vol 3, Sadness and Depression. New York Basic Books; 1980: pp. 281-7.

6. Hazan C, Shaver P. Romantic love conceptualized as an attachment process. J Pers Soc Psychol 1987;52:511-24.

7. Bartholomew K, Horowitz LM. Attachment styles among young adults: a test of a four-category model. J Pers Soc Psychol 1991;61:226-44.

8. Sümer N, Güngör D. [Psychometric evaluation of Adult attachment measures on Turkish samples and a cross-cultural comparison]. Türk Psikoloji Dergisi 1999;14:71-106. [Article in 
Turkish]

9. Kesebir S, Kavzoğlu SÖ, Üstündağ MF. [Attachment and psychopathology]. Psikiyatride Güncel Yaklaşımlar 2011;3:32142. [Article in Turkish]

10. Çalışır M. [The relationship of adult attachment theory and affect regulation strategies to depression]. Psikiyatride Güncel Yaklaşımlar 2009;1:240-55. [Article in Turkish]

11. Mikulincer M, Shaver PR. Attachment patterns in adulthood: structure, dynamics and change. New York: Guilford Press, 2007. 12. Selçuk E, Günaydın G, Sümer N, Uysal A. [A new scale developed to measure adult attachment dimensions: experiences in close relationships-revised (ECR-R) - Psychometric evaluation in a Turkish sample]. Türk Psikoloji Yazıları 2005;8:1-11. [Article in Turkish]

13. Sümer N, Güngör D. [The impact of perceived parenting styles on attachment styles, self -evaluations and close relationships]. Türk Psikoloji Dergisi 1999;14:35-58. [Article in Turkish]

14. Hisli N. [A study on the validity of Beck Depression Inventory]. Psikoloji Dergisi 1988;6:118-21. [Article in Turkish] 15. Wohlfarth T. Socioeconomic inequality and psychopathology: are socioeconomic status and social class interchangeable. Soc Sci Med 1997;45:399-410.

16. Öztürk MO. [Mental health and disorders]. Ankara: Nobel Tip Kitabevi, 2002: pp.566-70. [Book in Turkish].

17. Bifulco A, Kwon J, Jacobs C, Moran PM, Bunn A, Beer N. Adult attachment style as mediator between childhood neglect/abuse and adult depression and anxiety. Soc Psychiatry Psychiatr Epidemiol 2006;41:796-805. 